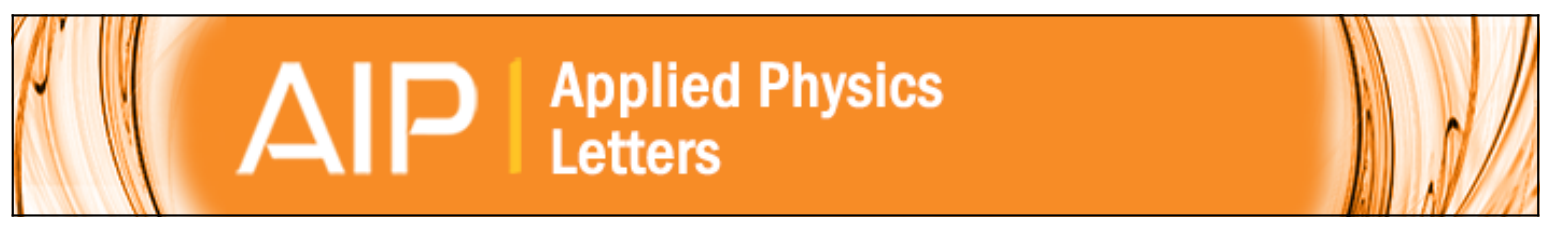

\title{
Ultrasharp ministop-band edge for subnanometer tuning resolution
}

N. Shahid, N. Speijcken, S. Naureen, M. Y. Li, M. Swillo, and S. Anand

Citation: Applied Physics Letters 98, 081112 (2011); doi: 10.1063/1.3559915

View online: http://dx.doi.org/10.1063/1.3559915

View Table of Contents: http://scitation.aip.org/content/aip/journal/apl/98/8?ver=pdfcov

Published by the AIP Publishing

\section{Articles you may be interested in}

Transmittance tuning by particle chain polarization in electrowetting-driven droplets

Biomicrofluidics 4, 043011 (2010); 10.1063/1.3516656

Pressure tuning the optical transmission properties of photonic band gap composites

Appl. Phys. Lett. 90, 071110 (2007); 10.1063/1.2454656

Photonic band tuning in two-dimensional photonic crystal slab waveguides by atomic layer deposition Appl. Phys. Lett. 89, 181108 (2006); 10.1063/1.2360236

Transmittance of a tunable filter at terahertz frequencies

Appl. Phys. Lett. 85, 5173 (2004); 10.1063/1.1829798

Thermally tuning of the photonic band gap of $\mathrm{SiO} 2$ colloid-crystal infilled with ferroelectric BaTiO 3

Appl. Phys. Lett. 78, 661 (2001); 10.1063/1.1344574

\section{A|P| Journal of}

Journal of Applied Physics is pleased to announce André Anders as its new Editor-in-Chief 


\title{
Ultrasharp ministop-band edge for subnanometer tuning resolution
}

\author{
N. Shahid, N. Speijcken, S. Naureen, M. Y. Li, ${ }^{a}$ M. Swillo, and S. Anand ${ }^{\text {b) }}$ \\ School of Information and Communication Technology, Royal Institute of Technology (KTH), Electrum 229, \\ 16440 Kista, Sweden
}

(Received 20 December 2010; accepted 4 February 2011; published online 24 February 2011)

\begin{abstract}
We propose and demonstrate a method that enables spectral tuning with subnanometer accuracy, and is based on the transmission ministop-band (MSB) in line-defect multimode photonic crystal (PhC) waveguides. The fabricated MSB filter has ultrasharp edges which show a $30 \mathrm{~dB}$ drop in transmission in a $4 \mathrm{~nm}$ wavelength span. The use of the ultrasharp MSB edge to (optically) determine PhC fabrication accuracy is demonstrated. The wavelength position of the MSB could be tuned by temperature, with a coefficient of $0.1 \mathrm{~nm} /{ }^{\circ} \mathrm{C}$. The spectral characteristics of the MSB realized in this work are promising for sensing, tuning, and modulation applications. (C) 2011 American Institute of Physics. [doi:10.1063/1.3559915]
\end{abstract}

Two-dimensional photonic crystal (2D-PhC) waveguides have attracted significant attention due to their extraordinary optical properties ${ }^{1}$ and for several potential applications including fluid sensing. ${ }^{2,3}$ InP-based $\mathrm{PhCs}$ have been investigated extensively since both active and passive components can be realized monolithically. The InP/InGaAsP/InP is of practical importance for integration due to its compatibility with conventional photonic components on InP substrate. ${ }^{4}$ $\mathrm{PhC}$ waveguides in this low refractive index contrast system are intrinsically lossy because the band-gap confined waveguide modes are mostly located above the light line even for infinitely deep holes. This makes the low index contrast system less suitable for applications which require high-Q cavities. However, by using high quality $\mathrm{PhC}$ fabrication techniques to reduce extrinsic optical losses other useful device applications can be realized. A sharp transmission band edge with large rejection ratios-at least $30 \mathrm{~dB}$ - could be potentially attractive for filtering, switching, sensing, tuning, and modulation functions. Different structures have been proposed to obtain sharp transmission band edges. ${ }^{5,6}$ Davano et $a l^{7}$ describe notch filters with sharp edges that use the transmission ministop-bands (MSBs) in PhC waveguides. A bandpass filter using a $\mathrm{PhC}$ waveguide with phase-shift elements has been proposed. ${ }^{8}$ Demonstrated transmission extinction ratios in Refs. 5 and 7 are about $20 \mathrm{~dB}$. In our case, a modified $\mathrm{PhC}$ fabrication process, which involves hole-reshaping, enables MSB PhC waveguide filters with high transmission extinction ratios $(\sim 30 \mathrm{~dB})$, and ultrasharp edges. A sharp and deep transmission MSB means better filter and mode selective characteristics. Such characteristics could also be beneficial for slow light, optical gain enhancement, and fluid sensing. Sharp edges of the transmission MSB can be used to investigate the sensitivity of the device to refractive index changes in the material, or in the holes, and to small changes in the geometric parameters of the PhC. In this work, the ultrasharp edge of the MSB is used as a sensitive monitor to determine the temperature dependence of refractive index of the waveguide material, and to detect subnanometer changes in hole-radius of the $\mathrm{PhC}$.

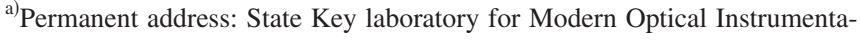
tion, Zhejiang University, Hangzhou 310027, China.

${ }^{b)}$ Electronic mail: anand@kth.se.
}

2D-PhC waveguides are typically made by introducing line defects in PhC slabs, and usually rely on the defect modes in the photonic band-gap (PBG) for their operation. $\mathrm{PhC}$ waveguides have been investigated extensively for their unique waveguiding properties. ${ }^{911}$ An interesting property is the mode-gap, or so-called MSB, which originates from energy transfer between forward and backward propagating modes in $2 \mathrm{D}-\mathrm{PhC}$ waveguides. ${ }^{11,12}$ In the frequency (wavelength) region of the mode-gap the transmission spectra of such waveguides show a characteristic dip, often referred to as the transmission MSB, or simply MSB. Such $\mathrm{PhC}$ waveguides, in addition to being compact, are attractive for many functional photonic devices which rely on mode coupling, such as filters, splitters, and switches. The mode-gap effect has been investigated not only from a fundamental physics point of view but also for device applications such as pulse compression, ${ }^{13}$ coarse wavelength selection, ${ }^{14}$ selective mirroring in $\mathrm{PhC}$ lasers, ${ }^{15}$ and fluid sensing. ${ }^{16}$

Figure 1 shows the dispersion diagram calculated by plane-wave expansion (PWE) method for a W3 (three missing rows of holes) $\mathrm{PhC}$ waveguide. The PWE calculations were made for an effective refractive index of 3.24 and airfill factor of $42 \% .^{12}$ These computations show a sufficient degree of accuracy for $\mathrm{PhC}$ waveguides in $\mathrm{InP} / \mathrm{InGaAsP} / \mathrm{InP}$, investigated here. ${ }^{17}$ As seen on Fig. 1, the mode-gap due to the coupling between the first and fifth order modes ${ }^{11,12}$ occurs around $u=0.27$, where $u$ is the normalized frequency

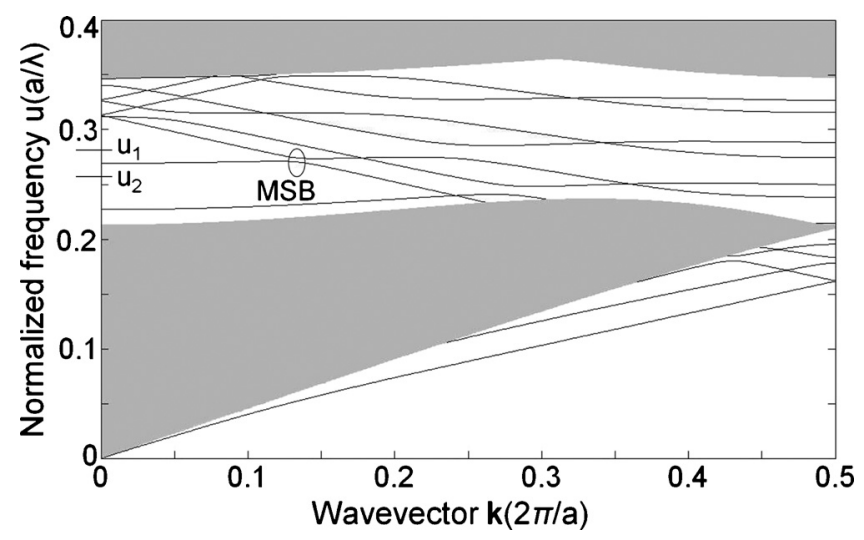

FIG. 1. Dispersion diagram of the $\mathrm{PhC}$ waveguide showing the region of interest; where $u_{1}=0.280$ and $u_{2}=0.266$. 


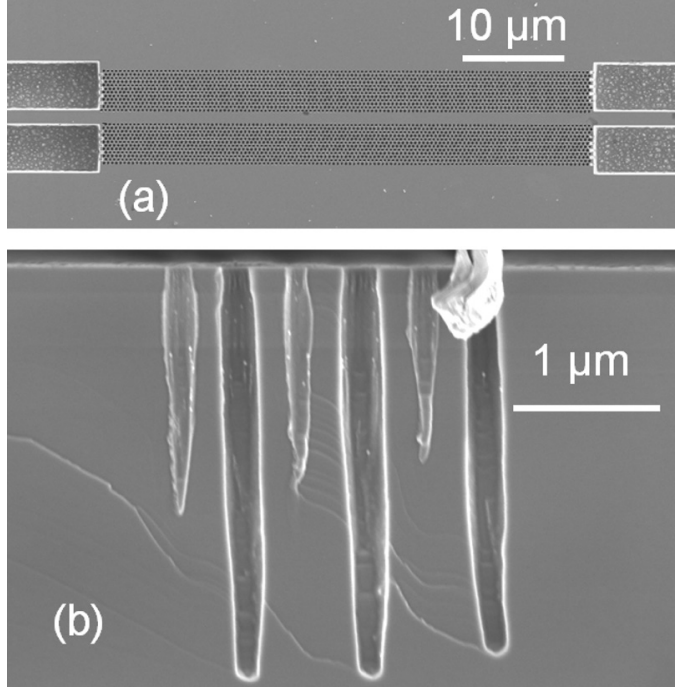

FIG. 2. (a) SEM top view of a fabricated PhC waveguide; part of the access ridge waveguides are also visible. (b) Cross-sectional SEM image of a representative $\mathrm{PhC}$ test structure showing near-vertical profiles; the test $\mathrm{PhC}$ structures were processed along with $\mathrm{PhC}$ waveguides.

( $u=a / \lambda ; a$ is the period). This value of $u$, for a period of 420 $\mathrm{nm}$ corresponds to a central wavelength of $\sim 1556 \mathrm{~nm}$. In this wavelength region a MSB appears in the transmission spectrum of the $\mathrm{PhC}$ waveguide. The temperature dependence of the MSB edge wavelengths was calculated from the temperature dependence of the effective refractive index $\left(n_{\text {eff }}\right)$ of the guided modes in the waveguide. ${ }^{18}$ At room temperature a value of $n_{\text {eff }}=3.24$ was calculated by the transfermatrix method, described in Ref. 18. Taking into account the temperature dependence of the refractive indices of the InP and GaInAsP layers, ${ }^{19,20}$ a value of $+2 \times 10^{-4} /{ }^{\circ} \mathrm{C}$ was obtained for $d n_{\mathrm{eff}} / d \mathrm{~T}$. $n_{\mathrm{eff}}$ calculated at different temperatures were used as input parameters in the $2 \mathrm{D}$ finite-difference time-domain simulations ${ }^{21}$ of the waveguide (transmission). From these simulations, the MSB-edge wavelength was found to shift linearly with temperature with a coefficient of $0.1 \mathrm{~nm} /{ }^{\circ} \mathrm{C}$.

The InP/InGaAsP/InP slab structure was grown by metal organic vapor phase epitaxy on a InP substrate. The InP cap and the InGaAsP (lattice matched to InP; $\lambda$ gap $=1.22 \mu \mathrm{m}$ ) core layers were $200 \mathrm{~nm}$ and $420 \mathrm{~nm}$ thick, respectively. The $\mathrm{W} 3 \mathrm{PhC}$ waveguides, with three missing rows in a triangular lattice (period $=420 \mathrm{~nm}$ ) of air-holes, are oriented in the $\Gamma$-K direction and were 120 row long. Here after, we use the term $\mathrm{PhC}$ waveguide to mean a W3 $\mathrm{PhC}$ waveguide. The $\mathrm{PhC}$ waveguide section was inserted in between two $1.2 \mu \mathrm{m}$ wide access-ridge waveguides, each being about $0.75 \mathrm{~mm}$ long. The PhC patterns were made by electron beam lithography using ZEP520 as the resist. An established process based on $\mathrm{Ar} / \mathrm{Cl}_{2}$ chemically assisted ion beam etching ${ }^{22}$ is used for high-aspect-ratio etching of the $\mathrm{PhC}$ waveguides. After etching, the $\mathrm{PhC}$ waveguides were annealed in ${\mathrm{a} \mathrm{PH}_{3}}$ ambient to reshape the etched $\mathrm{PhC}$ holes. Figure 2(a) shows a scanning electron microscopy (SEM) image of a fabricated $\mathrm{PhC}$ waveguide with 12 side rows of air-holes; the access ridge waveguides are also visible. Figure 2(b) shows a crosssectional view of a representative $\mathrm{PhC}$ test structure, which was processed along with $\mathrm{PhC}$ waveguides.

The $\mathrm{PhC}$ waveguides were optically characterized by the end-fire technigue A tunable laser with a spectral range of

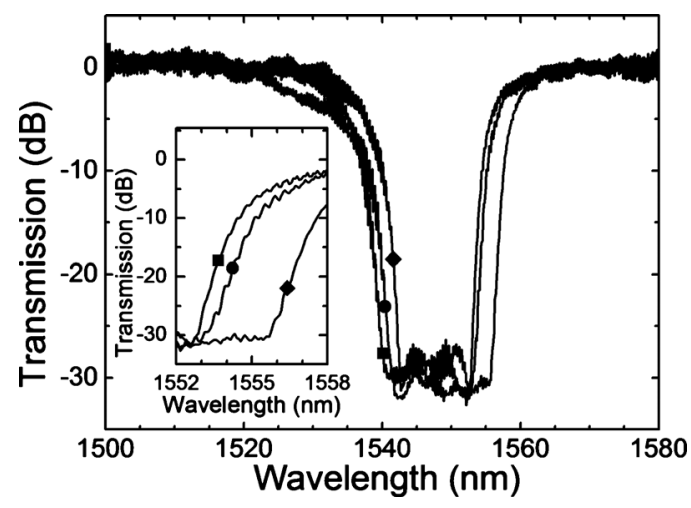

FIG. 3. Transmission spectra for $\mathrm{PhC}$ waveguides with 6 (diamond), 8 (circle), and 12 (square) side-rows of holes. Inset: part of the transmission spectra showing the long-wavelength edges of the MSBs. The spectra are normalized with respect to transmission at $\lambda=1570 \mathrm{~nm}$, outside the MSB.

1500-1580 nm was used as the light source. Polarizers were used at both input and output of the sample to ensure that only transverse electric mode was excited and collected, respectively. Figure 3 shows the measured transmission spectra of the $\mathrm{PhC}$ waveguides. The wavelength range where the MSBs occur is in good agreement with simulations (Fig. 1). The transmission extinction ratios of the MSBs are as high as $30 \mathrm{~dB}$, and the band-widths are around $12 \mathrm{~nm}$. The MSB edges are very sharp showing a $30 \mathrm{~dB}$ drop in transmission in a $\sim 4 \mathrm{~nm}$ wavelength span. In comparison, the edges of the MSB in the as-etched devices are about four times broader (not shown). The post-etch annealing step results in cylindrical hole shapes, and reduces the hole-depth fluctuations and hole-shape irregularities present in the as-etched $\mathrm{PhC}$ waveguides. An ultrasharp edge filter, recently reported by Talneau et $a l^{6}{ }^{6}$ shows a transmission drop of $25 \mathrm{~dB}$ on a 3 $\mathrm{nm}$ wavelength span. A comparable transmission drop within $2 \mathrm{~nm}$ wavelength span is observed in our $50 \mu \mathrm{m}$ long $\mathrm{PhC}$ waveguides.

The MSB can be used as a sensitive monitor to investigate the proximity effect in the electron beam lithography process. ${ }^{23}$ To address this, $\mathrm{PhC}$ waveguide patterns with 6,8 , and 12 side rows of holes were exposed using a constant electron beam dose. The resulting effect on the MSB characteristics can be investigated, because the lateral confinement of $\mathrm{PhC}$ waveguide modes is unaffected beyond 6 rows of air-holes. ${ }^{23}$ Consistent with the expected increase in holeradius due to the proximity effect, as the number of siderows in the waveguide increases the MSB shifts to shorter wavelengths (Fig. 3). The measured MSB-edge wavelength shift (inset, Fig. 3) between the waveguides with 12 and 8 side-rows is $0.8 \mathrm{~nm}$; and that between the 8 and 6 side-row waveguides is $2.5 \mathrm{~nm}$. In separate experiments, a predesigned $9 \mathrm{~nm}$ change in the hole-radius was found to result in a $23 \mathrm{~nm}$ wavelength shift in the MSB. Using this together with the data shown in Fig. 3, the increase in the hole-radius due to proximity effect is estimated. As the number of siderows increases from 6 to 8 , the estimated increase in the effective hole-radius is $1 \mathrm{~nm}$. The estimated increase in the hole radius is much smaller $(\sim 0.3 \mathrm{~nm})$ as the number of side-rows in the waveguides increases from 8 to 12 . These observations are qualitatively consistent with the expected influence of proximity effect. ${ }^{23}$ By ascribing the air-hole radius change to an average refractive index change in the 


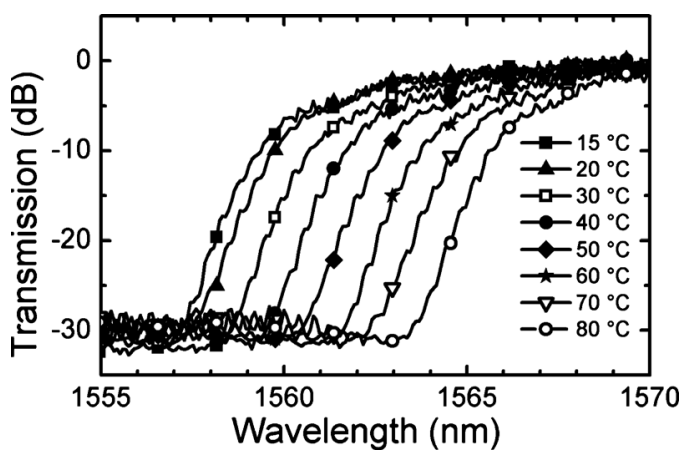

FIG. 4. Transmission spectra of a $\mathrm{PhC}$ waveguide at different temperatures. For the sake of clarity only one edge of the MSB is shown. The spectra are normalized with respect to transmission at $\lambda=1575 \mathrm{~nm}$, outside the MSB.

hole, $\Delta \lambda / \Delta \mathrm{n}$ is estimated to be $\sim 70 \mathrm{~nm}$ RIU (refractive index units).

Next, the spectral sensitivity of the MSB to refractive index changes was applied to determine the temperature dependence of the refractive index of the waveguide material. ${ }^{24}$ The sample temperature was varied from 15 to $80^{\circ} \mathrm{C}$, using a Peltier element. A systematic redshift in the MSB with temperature was observed (Fig. 4). From this data the temperature coefficient for the MSB-edge wavelength shift is determined as $\Delta \lambda / \Delta \mathrm{T}=0.1 \mathrm{~nm} /{ }^{\circ} \mathrm{C}$, in very good agreement with the theoretically calculated value. These results demonstrate temperature tuning of the MSB, and could be interesting for filters, modulators, and switches.

In conclusion, MSBs as deep as $30 \mathrm{~dB}$ in $50 \mu \mathrm{m}$ long $\mathrm{PhC}$ waveguides are demonstrated. In addition to the high extinction ratio, the MSBs have ultrasharp edges dropping by $30 \mathrm{~dB}$ in a $\sim 4 \mathrm{~nm}$ wavelength span. The MSB notch filter has a bandwidth of $\sim 12 \mathrm{~nm}$ and is centered around 1550 $\mathrm{nm}$. The use of the ultrasharp MSB edge as a sensitive monitor to (optically) determine PhC fabrication accuracy was demonstrated. Specifically, subnanometer changes in holeradius attributed to the proximity effect in electron beam lithography could be detected. The wavelength position of the MSB could be tuned by temperature, with a coefficient of $0.1 \mathrm{~nm} /{ }^{\circ} \mathrm{C}$. The spectral characteristics of the MSB realized in this work are promising for sensing, tuning, and modulation applications.
Support from the Swedish Strategic Research Foundation (SSF) and from the Swedish Research Council (VR) is gratefully acknowledged.

${ }^{1}$ J. D. Joannopoulos, S. G. Johnson, R. D. Meade, and J. N. Winn, Photonic Crystals: Molding the Flow of Light (Princeton University Press, Princeton, 2008).

${ }^{2}$ A. Di Falco, L. O'Faolain, and T. F. Krauss, Photonics Nanostruct. Fundam. Appl. 6, 38 (2008).

${ }^{3}$ A. Di Falco, L. O’Faolain, and T. F. Krauss, Appl. Phys. Lett. 94, 063503 (2009).

${ }^{4}$ R. Ferrini, D. Leuenberger, M. Mulot, M. Qiu, J. Moosburger, M. Kamp, A. Forchel, S. Anand, and R. Houdré, IEEE J. Quantum Electron. 38, 786 (2002).

${ }^{5}$ K. Cui, Y. Huang, G. Zhang, Y. Li, X. Tang, X. Mao, Q. Zhao, W. Zhang, and J. Pengllo, Appl. Phys. Lett. 95, 191901 (2009).

${ }^{6}$ A. Talneau, I. Sagnes, R. Gabet, Y. Jaouen, and H. Benisty, Appl. Phys. Lett. 97, 191115 (2010).

${ }^{7}$ M. Davano, A. Xing, J. W. Raring, E. L. Hu, and D. J. Blumenthal, IEEE J. Sel. Top. Quantum Electron. 12, 1164 (2006).

${ }^{8}$ C. Chen, X. Li, H. Li, K. Xu, J. Wu, and J. Lin, Opt. Express 15, 11278 (2007).

${ }^{9}$ M. Soljačić and J. D. Joannopoulos, Nature Mater. 3, 211 (2004).

${ }^{10}$ T. Baba, Nat. Photonics 2, 465 (2008).

${ }^{11}$ S. Olivier, M. Rattier, H. Benisty, C. J. M. Smith, R. M. De La Rue, T. F. Krauss, U. Oesterle, R. Houdré, and C. Weisbuch, Phys. Rev. B 63, 113311 (2001).

${ }^{12}$ M. Mulot, S. Anand, M. Swillo, M. Qiu, B. Jaskorzynska, and A. Talneau, J. Vac. Sci. Technol. B 21, 900 (2003)

${ }^{13}$ T. Cao, M. J. Cryan, P. S. Ivanov, D. Ho, B. Ren, I. J. Craddock, J. M. Rorison, and C. J. Railton, J. Opt. Soc. Am. B 24, 1575 (2007).

${ }^{14}$ M. Ayre, C. Cambournac, O. Khayam, H. Benisty, T. Stomeo, and T. F. Krauss, Photonics Nanostruct. Fundam. Appl. 6, 19 (2008).

${ }^{15}$ S. A. Moore, L. O'Faolain, T. P. White, and T. F. Krauss, Opt. Express 16, 1365 (2008)

${ }^{16}$ L. Cao, Y. Huang, X. Mao, F. Li, W. Zhang, and J. Peng, Chin. Phys. Lett. 25, 2101 (2008).

${ }^{17}$ M. Qiu, Appl. Phys. Lett. 81, 1163 (2002).

${ }^{18} \mathrm{P}$. Yeh, Optical Waves in Layered Media (Wiley, New York, 1988).

${ }^{19}$ E. Gini and H. Melchior, J. Appl. Phys. 79, 4335 (1996).

${ }^{20}$ J. Piprek, D. I. Babic, and J. E. Bowers, Appl. Phys. Lett. 68, 2630 (1996).

${ }^{21}$ M. Qiu, B. Jaskorzynska, M. Swillo, and H. Benisty, Microwave Opt. Technol. Lett. 34, 387 (2002).

${ }^{22}$ A. Berrier, M. Mulot, A. Talneau, R. Ferrini, R. Houdré, and S. Anand, J. Vac. Sci. Technol. B 25, 1 (2007).

${ }^{23}$ R. Wüest, F. Robin, P. Strasser, H. Jäckel, and D. Erni, J. Appl. Phys. 102, 083110 (2007).

${ }^{24}$ B. Wild, R. Ferrini, R. Houdré, M. Mulot, S. Anand, and C. J. M. Smith, Appl. Phys. Lett. 84, 846 (2004). 